\title{
Communication
}

\section{Triboelectric Energy Harvester Based on Stainless Steel/MoS and PET/ITO/PDMS for Potential Smart Healthcare Devices}

\author{
Carlos Gallardo-Vega ${ }^{1}\left(\mathbb{D}\right.$, Octavio López-Lagunes ${ }^{2}$, Omar I. Nava-Galindo ${ }^{3}{ }^{\circledR}$, Arxel De León ${ }^{4}{ }^{(}$, \\ Jorge Romero-García ${ }^{1}$, Luz Antonio Aguilera-Cortés ${ }^{3}$, Jaime Martínez-Castillo ${ }^{5}$ \\ and Agustín L. Herrera-May $2,5, *$ (D)
}

check for updates

Citation: Gallardo-Vega, C.;

López-Lagunes, O.;

Nava-Galindo, O.I.; De León, A.;

Romero-García, J.;

Aguilera-Cortés, L.A.;

Martínez-Castillo, J.;

Herrera-May, A.L. Triboelectric

Energy Harvester Based on Stainless Steel/MoS 2 and PET/ITO/PDMS for Potential Smart Healthcare Devices. Nanomaterials 2021, 11, 1533. https:// doi.org/10.3390/nano11061533

Academic Editor: Seok Woo Lee

Received: 3 May 2021

Accepted: 30 May 2021

Published: 10 June 2021

Publisher's Note: MDPI stays neutral with regard to jurisdictional claims in published maps and institutional affiliations.

Copyright: (c) 2021 by the authors. Licensee MDPI, Basel, Switzerland. This article is an open access article distributed under the terms and conditions of the Creative Commons Attribution (CC BY) license (https:/ / creativecommons.org/licenses/by/ $4.0 /)$.
1 Centro de Investigación en Química Aplicada, Saltillo 25294, Coahuila, Mexico; carlos.gallardo@ciqa.edu.mx (C.G.-V.); jorge.romero@ciqa.edu.mx (J.R.-G.)

2 Maestría en Ingeniería Aplicada, Facultad de Ingeniería de la Construcción y el Hábitat, Universidad Veracruzana, Boca del Río 94294, Veracruz, Mexico; olopzl@gmail.com

3 Departamento de Ingeniería Mecánica, DICIS, Universidad de Guanajuato,

Salamanca 36885, Guanajuato, Mexico; oi.navagalindo@ugto.mx (O.I.N.-G.); aguilera@ugto.mx (L.A.A.-C.)

4 CONACYT-Centro de Investigación en Química Aplicada, Saltillo 25294, Coahuila, Mexico; arxel.deleon@ciqa.edu.mx

5 Micro and Nanotechnology Research Center, Universidad Veracruzana, Boca del Río 94294, Veracruz, Mexico; jaimartinez@uv.mx

* Correspondence: leherrera@uv.mx; Tel.: +52-2297752000

\begin{abstract}
The smart healthcare devices connected with the internet of things (IoT) for medical services can obtain physiological data of risk patients and communicate these data in real-time to doctors and hospitals. These devices require power sources with a sufficient lifetime to supply them energy, limiting the conventional electrochemical batteries. Additionally, these batteries may contain toxic materials that damage the health of patients and environment. An alternative solution to gradually substitute these electrochemical batteries is the development of triboelectric energy harvesters (TEHs), which can convert the kinetic energy of ambient into electrical energy. Here, we present the fabrication of a TEH formed by a stainless steel substrate $(25 \mathrm{~mm} \times 15 \mathrm{~mm})$ coated with a molybdenum disulfide $\left(\mathrm{MoS}_{2}\right)$ film as top element and a polydimethylsiloxane (PDMS) film deposited on indium tin oxide coated polyethylene terephthalate substrate (PET/ITO). This TEH has a generated maximum voltage of $2.3 \mathrm{~V}$ and maximum output power of $112.55 \mu \mathrm{W}$ using a load resistance of $47 \mathrm{k} \Omega$ and a mechanical vibration to $59.7 \mathrm{~Hz}$. The proposed TEH could be used to power potential smart healthcare devices.
\end{abstract}

Keywords: triboelectric energy harvesting; internet of things; molybdenum disulfide $\left(\mathrm{MoS}_{2}\right)$; polydimethylsiloxane (PDMS); PET/ITO; smart healthcare device

\section{Introduction}

The smart healthcare devices connected to internet of things (IoT) can be used for continuous monitoring of the health of patients [1-4]. These devices with IoT allow the communication of several physiological data between patients and doctors [5-9]. Thus, these devices can be employed for monitoring the health of risk patients and taking immediately appropriate actions. The smart healthcare devices integrated with IoT could enhance the quality of the medical services to patients. In addition, these devices may be useful for healthcare in pandemic like COVID-19 [10-13]. Several smart healthcare devices are applied in clothes, wrist watches, bands and electronic-skin [14-18]. Most of these devices must contain materials with stretchable and wearable characteristics to be adjusted to different parts of the human body. In addition, novel wearable devices are demanding power between 1 and $100 \mu \mathrm{W}$ in function of their size and electronic components [19]. Generally, these devices are powered using conventional electrochemical batteries that have a limited operation time and may contain some toxic materials [20]. 
These toxic components can generate environmental contamination and health damage. Thus, renewable power sources are necessary to power smart healthcare devices. For this, energy harvesters are green energy sources that can convert the ambient energy into electrical energy using transduction mechanisms such as thermoelectric, electromagnetic, piezoelectric and triboelectric [21-24]. The energy harvesters can use diode rectifiers to convert the alternating current $(\mathrm{AC})$ in direct current $(\mathrm{DC})$. In addition, these energy harvesters may use capacitors to store the electrical energy.

The triboelectric energy harvesters (TEHs) have important advantages to be used in smart healthcare devices, including flexible and wearable materials, simple design, low cost and easy fabrication process. Commonly, TEHs can scavenge energy from low frequency sources [25,26]. For instance, Zhang et al. [27] reported a porous micro-nickel foam (PMNF)based TEH to scavenge natural vibration energy. This TEH $(50 \mathrm{~mm} \times 50 \mathrm{~mm}$ size) provides an open-circuit voltage and a short-circuit current of $187.8 \mathrm{~V}$ and $71.9 \mu \mathrm{A}$, respectively. Furthermore, the maximum output power of this TEH is $3.7 \mathrm{~W} / \mathrm{m}^{2}$ at a frequency of 13.9 Hz. On the other hand, Ahmed et al. [28] developed a flexible and stretchable selfpowered keyboard TEH based on urethane, silicone rubbers and carbon nanotubes (CNTs). This keyboard TEH can generate up to $2.5 \mathrm{~V}$ and a maximum output power of $0.3 \mu \mathrm{W}$. Zhang et al. [29] fabricated an expanded polytetrafluoroethylene (ePTFE)/Nylon-based TEH, which has a working area of $1 \mathrm{~cm}^{2}$. This ePTFE/Nylon TEH exhibits a maximum output power of $1.01 \mathrm{~mW} / \mathrm{cm}^{2}$ at $10 \mathrm{~Hz}$ with a load resistance of $1 \mathrm{M} \Omega$. Although of the great features of these TEHs, some of them have not simple designs and fabrication processes that can reduce their costs. Additionally, more investigations on TEHs using novel materials are required to improve their performance and decrease the fabrication costs $[30,31]$. Thus, future TEHs could be used in smart healthcare devices and wearable sensors. In this research topic, we propose a TEH composed by a top film of stainless steel/molybdenum disulfide $\left(\mathrm{MoS}_{2}\right)$ and bottom film of polydimethylsiloxane (PDMS) with substrate of tin-doped indium oxide (ITO) coated polyethylene terephthalate (PET).

\section{Materials and Methods}

The materials used in the fabrication process of a TEH were as follows: ethanol (solvent 99.9\%) and isopropyl alcohol (solvent 99.9\%) were purchased by J.T. Baker (Houston, Texas, USA); and ITO/PET substrates, ammonium molybdate tetrahydrate (83\%) and sodium sulfide hydrate $(60 \%)$ were acquired from Sigma-Aldrich Chemical Company (St. Louis, MO, USA); PDMS (Sylgard 184) with a volume ratio of 10:1 was obtained from Dow Corning (Campbell, CA, USA).

The synthesis of $\mathrm{MoS}_{2}$ was implemented using a modified method of Li et al. [32] and posterior exfoliation with ultrasound. The first step for molybdenum disulfide synthesis was adding ammonium molybdate $(250 \mathrm{mg})$ and sodium sulfide $(47.35 \mathrm{mg})$ in $25 \mathrm{~mL}$ of water with a few drops to $0.1 \mathrm{M} \mathrm{NaOH}$ to $\mathrm{pH} 7$. Then, the solution was mixed by the magnetic stirring machine $(30 \mathrm{~min})$. After the mixed solution was put into a teflonlined stainless steel autoclave and left to react for $24 \mathrm{~h}$ at $180^{\circ} \mathrm{C}$, the product was then washed three times with ethanol by centrifugation ( $25 \mathrm{~min}$ at $13,000 \mathrm{rpm}$ ) and dried at RT. Subsequently, the molybdenum disulfide (2 gm) was added in isopropyl alcohol (100 mL) and then placed for a sonication process for $3 \mathrm{~h}$ at 30 amplitude. In order to scatter the $\mathrm{MoS}_{2}$ from the isopropyl alcohol, the sample was left to rest for a day. Finally, the precipitate $\left(\mathrm{MoS}_{2}\right)$ was separated from the supernatant and then left to dry (RT). Finally, $\mathrm{MoS}_{2}(500 \mathrm{mg})$ and isopropyl alcohol $(5 \mathrm{~mL})$ were mixed to obtain a $\mathrm{MoS}_{2}$ dispersion by ultrasound for $30 \mathrm{~min}$. Subsequently, the solution was spin coated (1 min at $100 \mathrm{rpm})$ on the stainless steel substrate and then dried at RT.

The fundamental operation of TEH consists of the vertical contact separation of their layers, which is established by contact electrification and electrostatic induction. Figure 1 shows a schematic of the TEH, wherein two active materials and two electrodes are placed as a sandwich structure. The two active materials, $\mathrm{MoS}_{2}$ and PDMS are assigned as the top and bottom active materials, respectively. Each active material has a thickness, 
defined as $d_{1}$ for the MoS 2 and $d_{2}$ for the PDMS, and a separation distance $\left(d_{3}\right)$ between them. In the origin position, the active materials has no generation nor induction of electrical charge. When the $\mathrm{MoS}_{2}$ and PDMS films are in contact due to an external force, electrons are transferred from the $\mathrm{MoS}_{2}$ surface to the PDMS surface. At the pressed state, these electrons generate a positive charge in the surface of $\mathrm{MoS}_{2}$ and a negative charge on the surface of PMDS. These charges are better known as triboelectric charges $(\sigma)$. In the short-circuit condition, an induced charge $\left(\sigma^{\prime}\right)$ is generated once the top and bottom electrodes are connected, flowing a current among them. The induced positive and negative charges are accumulated on the top and bottom electrodes, respectively. Thus, a positive current is generated, and the original separation $\left(\mathrm{d}_{3}\right)$ is changed to a small separation $\left(d^{\prime}\right)$ during the releasing state. At the released state, the maximum value of the induced charge $\left(\sigma_{\mathrm{m}}\right)$ is obtained once the original separation distance $\left(\mathrm{d}_{3}\right)$ is reached. Pressing the TEH again results in the reduction of $d_{3}$, leaving the top electrode with a higher electrical potential than that of the lower electrode. Thus, electrons start to move from the bottom electrode to the top electrode, decreasing the number of induced charges and releasing a negative current. When the $\mathrm{MoS}_{2}$ and PDMS come back in contact, all the induced charges counteract each other.

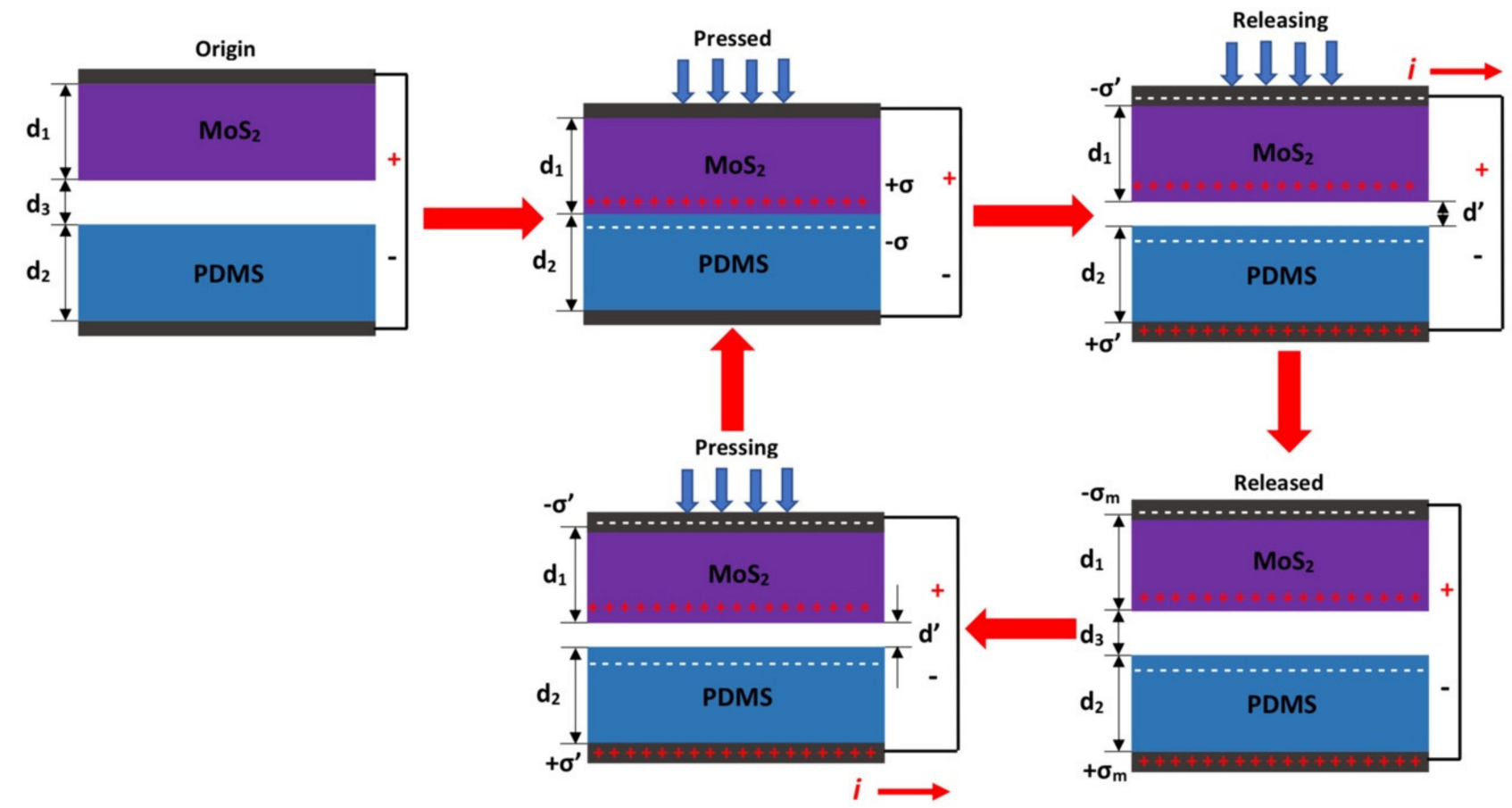

Figure 1. Schematic view of the fundamental operation in short-circuit condition of the TEH based on stainless steel/MoS 2 and PET/ITO/PDMS.

In the open circuit condition, the $\mathrm{MoS}_{2}$ surface is positively charged, and the PDMS surface is negatively charged. Once the relative positions of the $\mathrm{MoS}_{2}$ and PDMS films are altered, the electric potential difference is changed. Therefore, electrons move through the electrodes while the maximum electrical output is obtained. Figure 2 depicts a schematic view of the setup to measure the electrical response of the triboelectric energy harvester.

A large TEH area can increase the charges accumulated of its triboelectric layers, improving the output power [33]. However, the design of our TEH area was limited due to the working size of the spin coating machine. Thus, we used PET/ITO/PDMS and stainless steel $/ \mathrm{MoS}_{2}$ films with a rectangular area of $25 \mathrm{~mm} \times 15 \mathrm{~mm}$. This area size is similar to that reported in other TEHs to harvest energy from human body motions [34-39].

The PET/ITO substrate was washed with ethanol three times using an ultrasonic bath (5 min). The stainless steel substrate was cleaned with chloroform into the ultrasonic washer for $5 \mathrm{~min}$ and $10 \mathrm{~min}$. Later, two more times (5 min and $10 \mathrm{~min}$ ) using ethanol. 
Finally, the substrates were dried using compressed air and carried out cleaning and drying at $25{ }^{\circ} \mathrm{C}$.
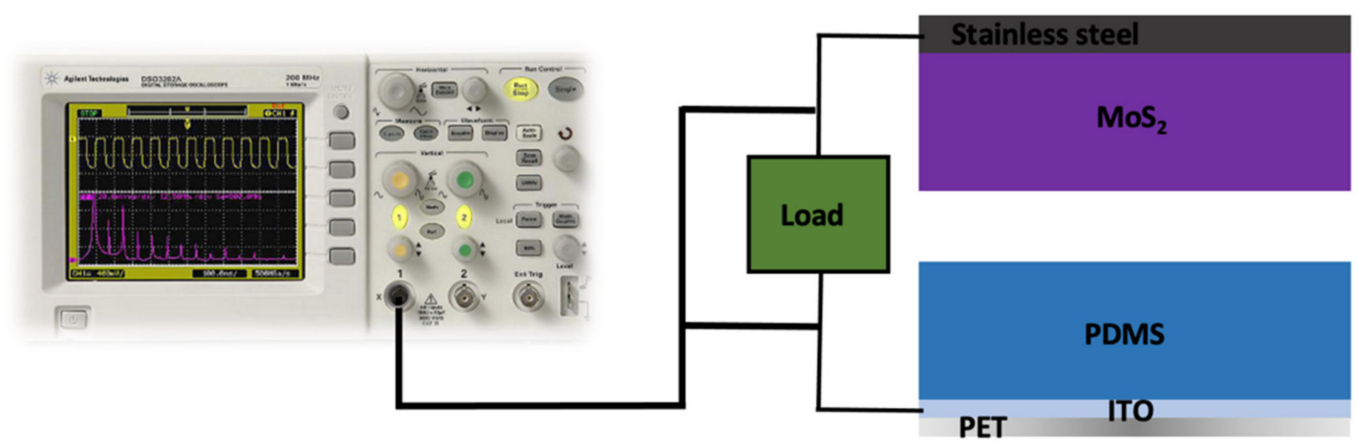

Figure 2. Schematic view of the experimental setup to measure the electrical response of the triboelectric energy harvester.

On the other hand, the PDMS film was obtained by mixing the PDMS (100 mg) and curing agent $(10 \mathrm{mg})$ in chloroform $(3 \mathrm{~mL})$. Later, PDMS $(100 \mathrm{mg} / \mathrm{mL})$ solution was mixed using the ultrasonic machine ( $30 \mathrm{~min}$ ). Then, the PDMS film was coated on the PET/ITO substrate employing spin coating ( $1 \mathrm{~min}$ at $100 \mathrm{rpm}$ ) and heated in an oven for $1 \mathrm{~h}$ at $150{ }^{\circ} \mathrm{C}$ to PDMS crosslinking. Figure 3 shows the preparation procedure steps of the bottom and top films of the TEH.

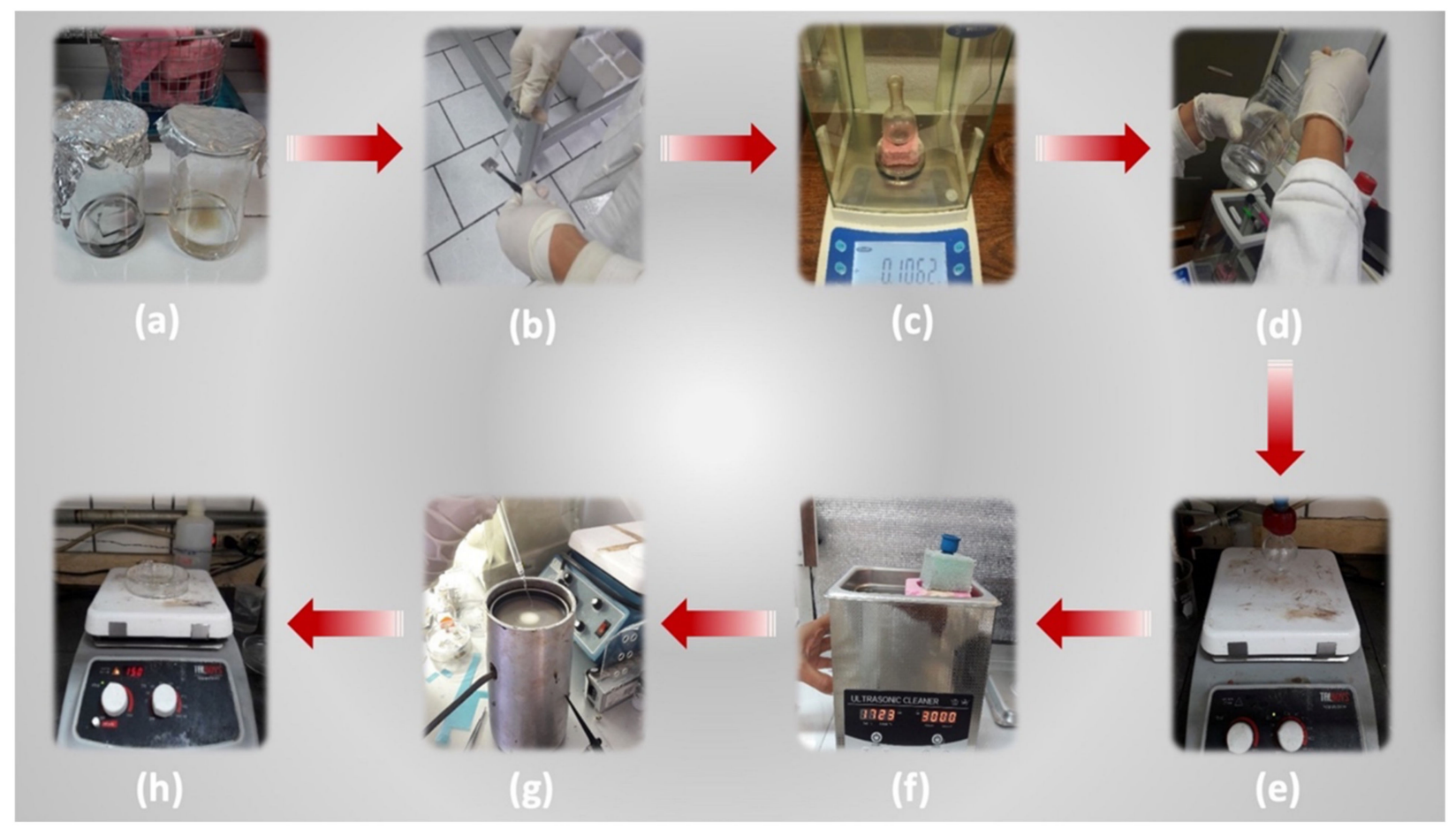

Figure 3. Images of the preparation procedure steps for the top and bottom films of the TEH: (a) substrates cleaning; (b) substrates drying; (c) samples weighing; (d) solution preparation; (e) magnetic stirring; (f) ultrasonic bathing; (g) spin coating; (h) drying.

An electromagnetic shaker was constructed using a woofer coupled (CIQA, Saltillo, Coahuila, Mexico) to a signal amplifier TPA3118 (Texas Instruments, Dallas, TX, USA). A function generator (METEX model MXG-9810A) (METEX, Seoul, Korea) is employed to obtain the vibration amplitude and frequency of the shaker. The two layers of proposed TEH were mechanically excited using the shaker and its output voltage was measured using an oscilloscope (KEYSIGHT technologies model DSO3102A) (KEYSIGHT Technologies, 
Santa Rosa, CA, USA). Figure 4 shows the electrodes of the bottom and upper layers of the TEH connected to the oscilloscope.

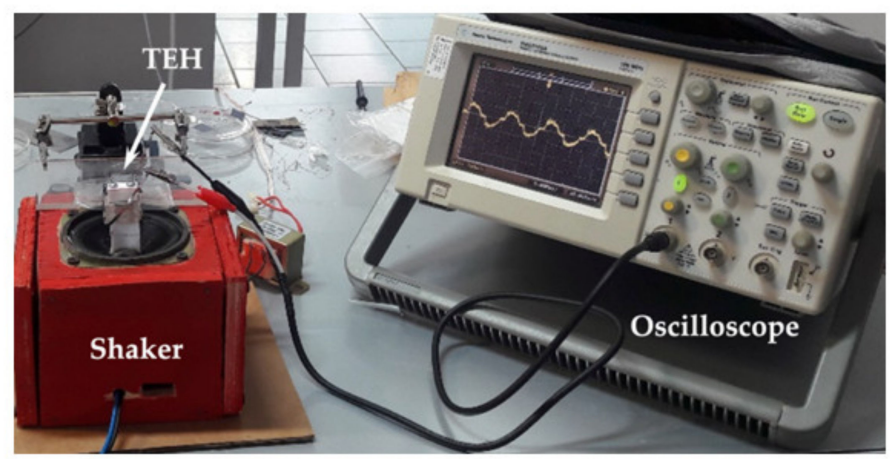

(a)

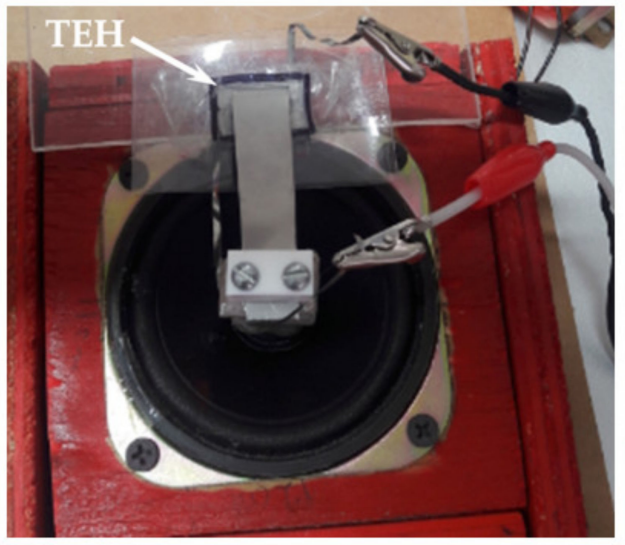

(b)

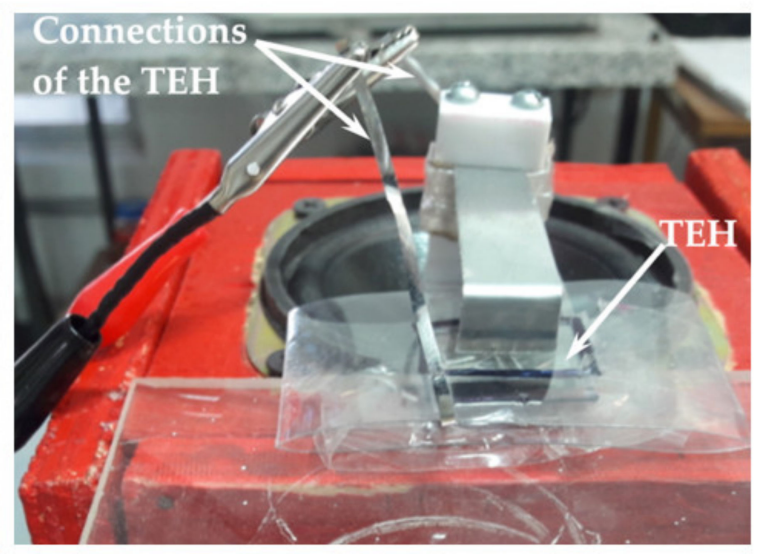

(c)

Figure 4. Experimental setup to measure the output voltage of the triboelectric energy harvester: (a) shaker, TEH and oscilloscope, (b) upper view of the TEH mounted on the shaker and (c) electrical connections of the TEH.

The X-ray diffraction (XRD) study of $\mathrm{MoS}_{2}$ material was performed on an Eco D8 Advance of Bruker. The data were recorded in the range of $3-90^{\circ} 2 \theta$, at a rate $0.01^{\circ} / \mathrm{min}$, $40 \mathrm{KV}$ voltage and $25 \mathrm{~mA}$ of emission current. The $\mathrm{MoS}_{2}$ morphology was determined by transmission electron microscopy (TEM) with the FEI Titan microscope at $300 \mathrm{KV}$, by casting few drops of a dispersion of materials in isopropyl alcohol $(0.1 \mathrm{mg} / \mathrm{mL})$ on a Lacey carbon grid. AFM morphological study was performed on a Dimension ${ }^{\mathrm{TM}} 3100$ from Digital Instruments with a Pt-coated Si tip with a $15 \mathrm{~nm}$ nominal radius model (OSCM-PT Bruker). The images were obtained at a scanning rate (256 lines) of $1 \mathrm{~Hz}$.

\section{Results and Discussion}

The XRD analysis of $\mathrm{MoS}_{2}$ shows the reflection at $2 \theta=14.3,29.03,32.6,33.51,35.87$, $39.54,44.15,49.79,55.98,58,34,60.15,70.14$ and 72.79 corresponded to $\mathrm{MoS}_{2}$ crystalline planes respectively: (002), (004), (100), (101), (102), (103), (006), (105), (106), (110), (008), (108) and (203) (JCDPS 37-1492). This result demonstrated the total conversion of the precursors (ammonium molybdate and sodium sulfide) into $\mathrm{MoS}_{2}$, without signals or other associated reflections for impurities (Figure 5).

The morphological analysis was obtained by TEM (Figure 6), where we observed a few transparent and exfoliated layers of $\mathrm{MoS}_{2}$ (indicated as dashed regions), coexisting with stacked sheets (darkest regions). This indicate partial exfoliation for $\mathrm{MoS}_{2}$. The HRTEM shows the lattice spacing of $0.62 \pm 0.002$ that corresponds to (002) facet of $\mathrm{MoS}_{2}$ (JCDPS 37-1492). Figure 7 shows the morphological analysis of PDMS film by tapping mode. The 
PDMS presents uniform morphology with root mean square roughness $\mathrm{Rq}=0.775 \mathrm{~nm}$ and roughness average $\mathrm{Ra}=0.611 \mathrm{~nm}$.

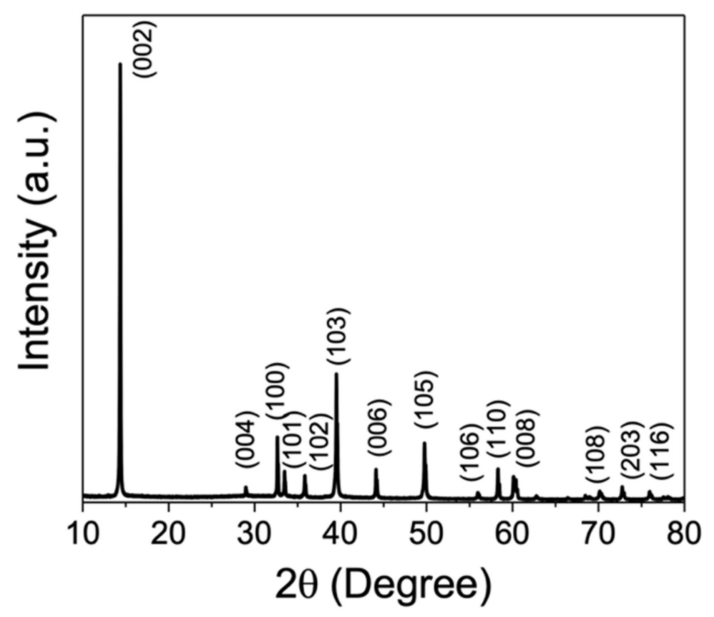

Figure 5. XRD result of $\mathrm{MoS}_{2}$ film of the triboelectric energy harvester.

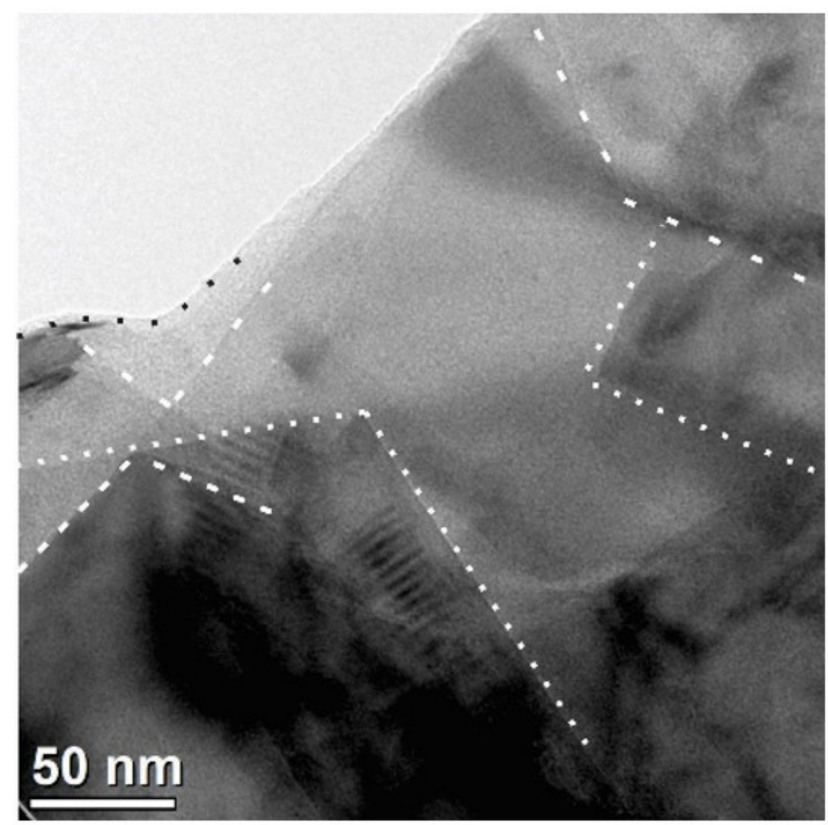

(a)

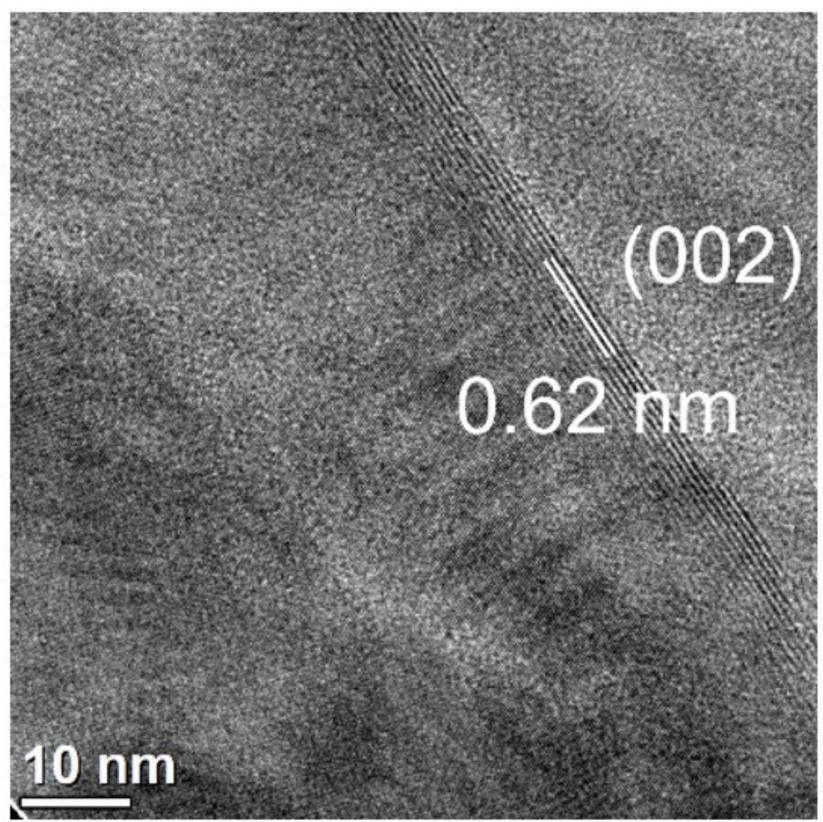

(b)

Figure 6. Morphological analysis of molybdenum disulfide film: (a) TEM and (b) HRTEM of the $\mathrm{MoS}_{2}$ crystals.

Next, we connected to the TEH a load resistance of $47 \mathrm{k} \Omega$ to measure its output voltage. For this, a mechanical vibration to $59.7 \mathrm{~Hz}$ was applied. Figure 8 depicts the peak-peak output voltage of the TEH during $0.24 \mathrm{~s}$. Based on this response, the maximum output voltage of the TEH is close to $2.3 \mathrm{~V}$. Thus, the maximum output power and power density are $112.55 \mu \mathrm{W}$ and $30 \mu \mathrm{W} / \mathrm{cm}^{2}$, respectively. This power overcomes the range from 1 to $100 \mu \mathrm{W}$ that demands several smart healthcare devices reported in the literature [19]. However, future works must include more investigations about performance and reliability of TEHs based on stainless steel/MoS 2 and PET/ITO/PDMS. 


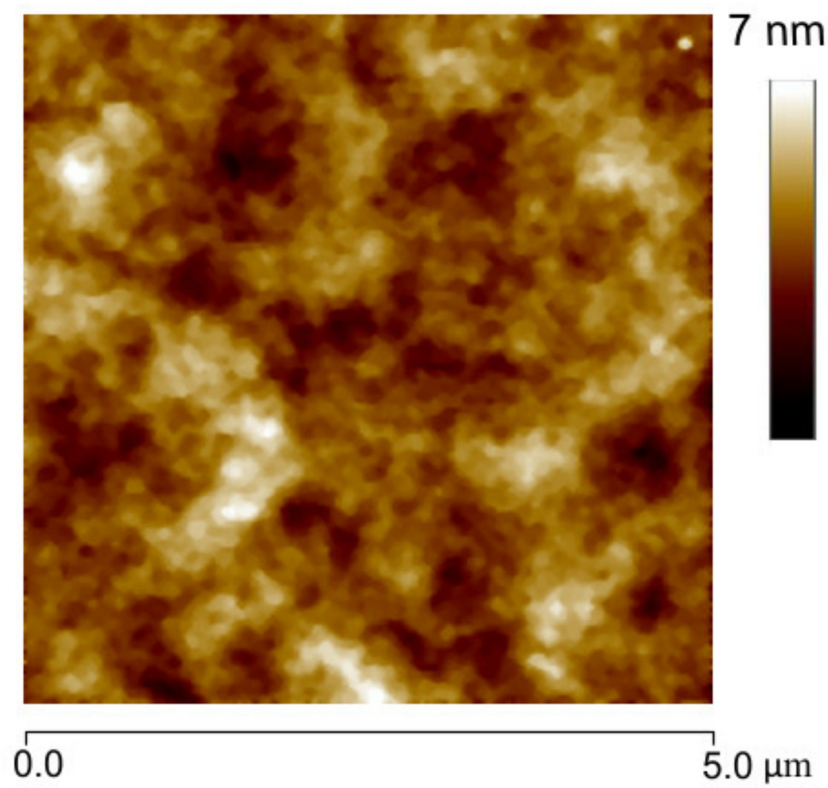

Figure 7. Morphological characteristics tapping image of PDMS film.

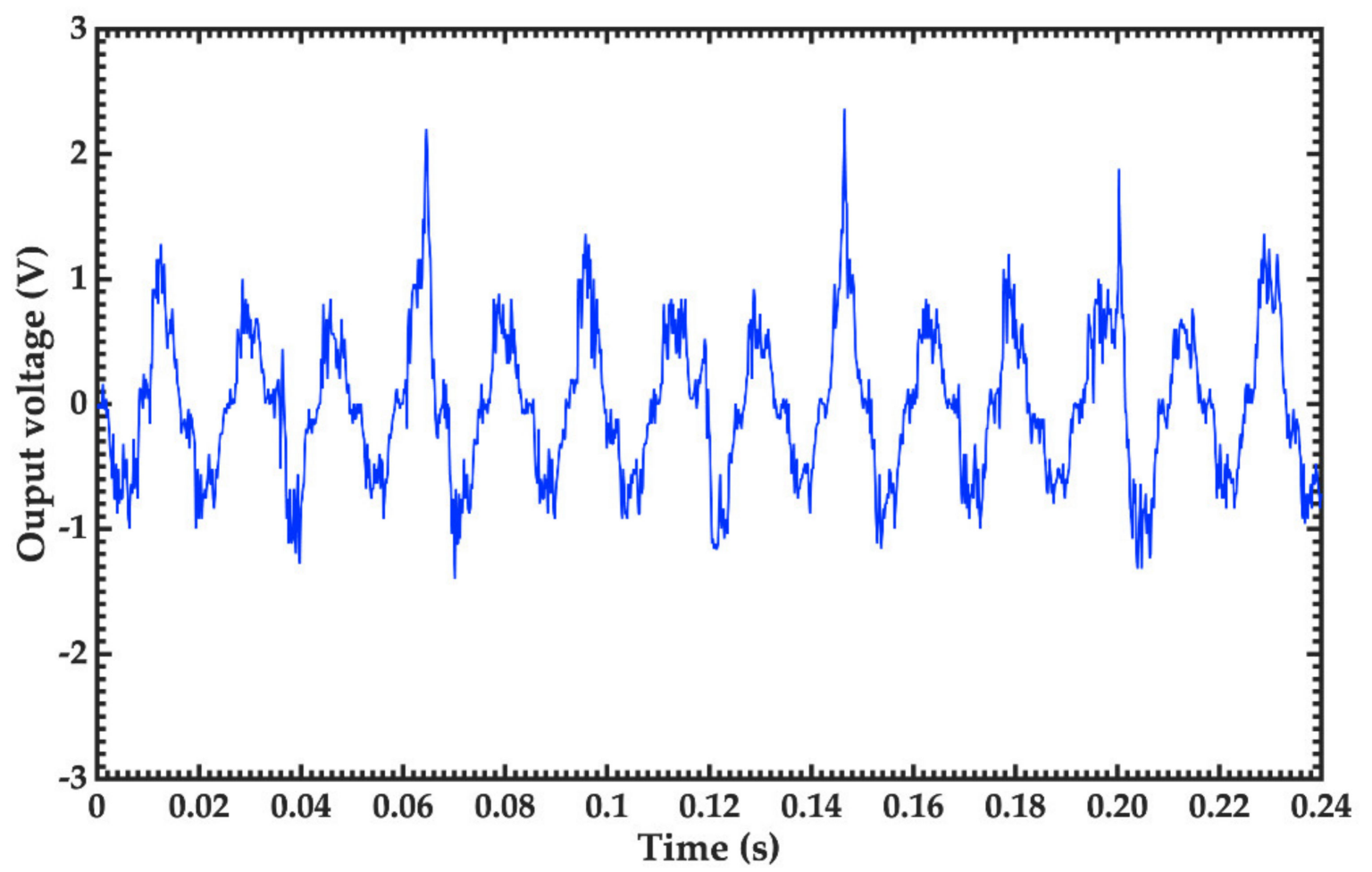

Figure 8. Measurements of the output voltage of the triboelectric energy harvester using a load resistance of $47 \mathrm{k} \Omega$ and a mechanical excitation at $59.7 \mathrm{~Hz}$.

Table 1 depicts the main parameters of the performance of our TEH device in comparison with other devices that include $\mathrm{MoS}_{2}$ films. These parameters consider the materials films, contact area, test frequency, resistance, voltage and power density. Our TEH shows good performance based on a simple and low-cost fabrication process. 
Table 1. Comparison of the main parameters of different TEH devices that contain $\mathrm{MoS}_{2}$ film.

\begin{tabular}{|c|c|c|c|c|c|c|}
\hline $\begin{array}{l}\text { TEH Structure } \\
\text { Materials }\end{array}$ & $\begin{array}{l}\text { Contact Area } \\
\left(\mathrm{cm}^{2}\right)\end{array}$ & $\begin{array}{l}\text { Frequency } \\
(\mathbf{H z})\end{array}$ & $\begin{array}{l}\text { Resistance } \\
\quad(\Omega)\end{array}$ & $\begin{array}{l}\text { Voltage } \\
\text { (V) }\end{array}$ & $\begin{array}{l}\text { Power Density } \\
\quad\left(\mu \mathrm{W} / \mathrm{cm}^{2}\right)\end{array}$ & Ref. \\
\hline $\begin{array}{c}\mathrm{PET} / \mathrm{Al} / \mathrm{PI} \\
\text { Glass/Al/PI/MoS } 2: \mathrm{PI} / \mathrm{PI}\end{array}$ & 3.75 & 5 & $5 \times 10^{6}$ & 120 & 2570 & [40] \\
\hline $\begin{array}{l}\mathrm{Cu} / \mathrm{PVDF} / \mathrm{MoS}_{2-} \\
\text { cellulose } \\
\text { paper } / \mathrm{PVDF} / \mathrm{Cu} \\
\mathrm{Cu} / \text { Polyimide }\end{array}$ & 9 & - & $1 \times 10^{6}$ & 50 & 180 & [41] \\
\hline $\begin{array}{c}\text { PET/PPy } \\
\text { PET /ITO/PDMS/PVDF- } \\
\text { ferroelectric/ } \mathrm{MoS}_{2}\end{array}$ & 1 & 10 & $10 \times 10^{6}$ & -80 & 455 & [42] \\
\hline $\begin{array}{c}\text { Al-MoS }- \text { Glue/Paper } \\
\text { Al/Graphite- } \\
\text { Glue/Paper }\end{array}$ & 9 & 3 & $3.2 \times 10^{6}$ & 3.82 & $7.44 \times 10^{-2}$ & [43] \\
\hline $\begin{array}{c}\text { ITO:PET/PVDF- } \\
\text { TrFE/MoS } 2 \\
\text { ITO:PET/Nylon11/ } \mathrm{MoS}_{2} \\
\end{array}$ & 1 & 6.5 & $10 \times 10^{6}$ & 145 & $5 \times 10^{4}$ & [44] \\
\hline $\begin{array}{c}\text { Steel-MoS } 2 \\
\text { PET/ITO/PDMS }\end{array}$ & 3.75 & 59.7 & $47 \times 10^{3}$ & 2.3 & 30 & Our work \\
\hline
\end{tabular}

\section{Conclusions}

A TEH integrated by stainless steel/ $\mathrm{MoS}_{2}$ and PET/ITO/PDMS films was presented. This TEH was developed using a simple and low-cost fabrication process. XRD and morphological analysis of the $\mathrm{MoS}_{2}$ film were implemented. In addition, morphological characteristics of PDMS film was investigated using AFM. The electrical response of the proposed energy harvester was measured applying a mechanical excitation to $59.7 \mathrm{~Hz}$ and a load resistance of $47 \mathrm{k} \Omega$. The maximum voltage and power density of the TEH were $2.3 \mathrm{~V}$ and $30 \mu \mathrm{W} / \mathrm{cm}^{2}$, respectively. This electrical performance of the energy harvester could allow its potential application into smart healthcare device.

Author Contributions: Methodology, C.G.-V.; conceptualization, J.R.-G. and L.A.A.-C.; investigation, J.M.-C.; formal analysis A.D.L. and O.I.N.-G.; validation O.L.-L.; writing-review and editing, A.L.H.-M. All authors have read and agreed to the published version of the manuscript.

Funding: This research was funded by FONCYT-COECyT through COAH-2020-C14-C024 and PROFEXCE 2020 “DES Técnica Veracruz” through grant 30MSU0940B-21.

Data Availability Statement: Request the corresponding author of this article.

Acknowledgments: We acknowledge to Tai Say Puon de la Cruz by her contribution in the preparation of the materials. Octavio Lagunes-López and Omar I. Nava-Galindo thank for the scholarship received by CONACYT during their master and doctoral studies.

Conflicts of Interest: The authors declare no conflict of interest.

\section{References}

1. Tang, W.; Ren, J.; Deng, K.; Zhang, Y. Secure data aggregation of lightweight E-healthcare IoT devices with fair incentives. IEEE Internet Things J. 2019, 6, 8714-8726. [CrossRef]

2. Ardalan, S.; Hosseinifard, M.; Vosough, M.; Golmohammadi, H. Towards smart personalized perspiration analysis: An IoTintegrated cellulose-based microfluidic wearable patch for smartphone fluorimetric multi-sensing of sweat biomarkers. Biosens. Bioelectron. 2020, 168, 112450. [CrossRef]

3. Jaleel, A.; Mahmood, T.; Hassan, M.A.; Bano, G.; Khurshid, S.K. Towards medical data interoperability through collaboration of healthcare device. IEEE Access 2020, 8, 132302-132319. [CrossRef]

4. Ahmed, I.; Ahmad, M.; Jeon, G.; Piccialli, F. A framework for pandemic prediction using big data analytics. Big Data Res. 2021, 25, 100190. [CrossRef] 
5. Aski, V.J.; Sonawane, S.S.; Soni, U. IoT Enabled Ubiquitous Healthcare Data Acquisition and Monitoring System for Personal and Medical Usage Powered by Cloud Application: An Architectural Overview. In Recent Developments in Machine Learning and Data Analytics; Kalita, J., Balas, V., Borah, S., Pradhan, R., Eds.; Advances Intelligent Systems and Computing 2019; Springer: Singapore, 2019; Volume 740. [CrossRef]

6. Tolba, A.; Said, O.; Al-Makhadmeh, Z. MDS: Multi-level decision system for patient behavior analysis based on wearable device information. Comput. Commun. 2019, 147, 180-187. [CrossRef]

7. Baker, S.B.; Xiang, W.; Atkinson, I. Internet of things for smart healthcare: Technologies, challenges, and opportunities. IEEE Access 2017, 5, 26521-26544. [CrossRef]

8. Zhang, C.; Cho, H.; Chen, C. Emergency-level-based healthcare information offloading over fog network. Peer-to-Peer Netw. Appl. 2020, 13, 16-26. [CrossRef]

9. Elmisery, A.M.; Rho, S.; Aborizka, M. A new computing environment for collective privacy protection from constrained healthcare devices to IoT cloud services. Cluster Comput. 2019, 22, 1611-1638. [CrossRef]

10. Udgata, S.K.; Suryadevara, N.K. COVID-19, Sensors, and Internet of Medical Things (IoMT). In Internet of Things and Sensor Network for COVID-19; SpringerBriefs in Applied Sciences and Technology; Springer: Singapore, 2021. [CrossRef]

11. Tripathy, A.K.; Mohapatra, A.G.; Mohanty, S.P.; Kougianos, E.; Joshi, A.M.; Das, G. EasyBand: A wearable for safety-aware mobility during pandemic outbreak. IEEE Consum. Electron. Mag. 2020, 9, 57-61. [CrossRef]

12. Hossam, A.; Magdy, A.; Fawzy, A.; Abd El-Kader, S.M. An Integrated IoT System to Control the Spread of COVID-19 in Egypt. In Proceedings of the International Conference on Advanced Intelligent Systems and Informatics 2020; Hassanien, A.E., Slowik, A., Snášel, V., El-Deeb, H., Tolba, F.M., Eds.; AISI 2020; Advances in Intelligent Systems and Computing; Springer: Cham, Switzerland, 2021; Volume 1261. [CrossRef]

13. Udgata, S.K.; Suryadevara, N.K. Advances in Sensor Technology and IoT Framework to Mitigate COVID-19 Challenges. In Internet of Things and Sensor Network for COVID-19; Springer Briefs in Applied Sciences and Technology; Springer: Singapore, 2021. [CrossRef]

14. Lim, T.; Kim, Y.; Jeong, S.M.; Kim, C.H.; Kim, S.M.; Park, S.Y.; Yoon, M.H.; Ju, S. Human sweat monitoring using polymer-based fiber. Sci. Rep. 2019, 9, 17294. [CrossRef]

15. Cheung, T.W.; Li, L. A review of hollow fibers in application-based learning: From textiles to medical. Text. Res. J. 2019, 89, 237-253. [CrossRef]

16. Goldberg, A.; Ho, J.W.K. Hactive: A smartphone application for heart rate profiling. Biophys. Rev. 2020, 12, 777-779. [CrossRef]

17. Yuan, J.F.; Zhu, R.; Li, G.Z. Self-powered electronic skin with multisensory functions based on thermoelectric conversion. Adv. Mater. Technol. 2020, 5, 2000419. [CrossRef]

18. Mohammadifar, M.; Tahernia, M.; Yang, J.H.; Koh, A.; Cho, S. Biopower-on-skin: Electricity generation from sweat-eating bacteria for self-powered E-Skins. Nano Energy 2020, 75, 104994. [CrossRef]

19. Dahiya, A.S.; Thireau, J.; Boudaden, J.; Lal, S.; Gulzar, U.; Zhang, Y.; Gil, T.; Azemard, N.; Ramm, P.; Kiessling, T.; et al. Review-energy autonomous wearable sensors for smart healthcare: A review. J. Electrochem. Soc. 2020, 167, 037516. [CrossRef]

20. Sethurajan, M.; Gaydardzhiev, S. Bioprocessing of spent lithium ion batteries for critical metals recovery-A review. Resour. Conserv. Recycl. 2021, 165, 105225. [CrossRef]

21. Shaukat, R.A.; Saqib, Q.M.; Khan, M.U.; Chougale, M.Y.; Bae, J. Bio-waste sunflower husk powder based recycled triboelectric nanogenerator for energy harvesting. Energy Rep. 2021, 7, 724-731. [CrossRef]

22. Lee, H.; Roh, J.-S. Charging device for wearable electromagnetic energy-harvesting textiles. Fash. Text. 2021, 8, 5. [CrossRef]

23. Zhou, L.; Yang, T.; Zhu, L.; Li, W.; Wang, S.; Hou, X.; Mao, X.; Wang, Z.L. Piezoelectric nanogenerators nanogenerators with high performance again harsh conditions based on tunable $\mathrm{N}$ doped $4 \mathrm{H}-\mathrm{SiC}$ nanowire arrays. Nano Energy 2021, 83, 105826. [CrossRef]

24. Lee, D.; Kim, I.; Kim, D. Hybrid tribo-thermoelectric generator for effectively harvesting thermal energy activated by the shape memory alloy. Nano Energy 2021, 82, 105696. [CrossRef]

25. Chen, H.; Bai, L.; Li, T.; Zhao, C.; Zhang, J.; Zhang, N.; Song, G.; Gan, Q.; Xu, Y. Wearable and robust triboelectric nanogenerator based on crumpled gold films. Nano Energy 2018, 46, 73-80. [CrossRef]

26. Zhang, H.; Lu, Y.; Ghaffarinejad, A.; Basset, P. Progressive contact-separate triboelectric nanogenerator based on conductive polyurethane foam regulated with a Bennet doubler conditioning circuit. Nano Energy 2018, 51, 10-18. [CrossRef]

27. Zhang, L.; Jin, L.; Zhang, B.; Deng, W.; Pan, H.; Tang, J.; Zhu, M.; Yang, W. Multifunctional triboelectric nanogenerator based on porous micro-nickel foam to harvest mechanical energy. Nano Energy 2015, 16, 516-523. [CrossRef]

28. Ahmed, A.; Zhang, S.L.; Hassan, I.; Saadatnia, Z.; Zi, Y.; Zu, J.; Wang, Z.L. A washable, stretchable, and self-powered humanmachine interfacing triboelectric nanogenerator for wireless communications and soft robotics pressure sensor arrays. Extreme Mech. Lett. 2017, 13, 25-35. [CrossRef]

29. Zhang, Z.; Xu, Y.; Wang, D.; Yang, H.; Guo, J.; Turng, L.-S. Enhanced performance of an expanded polytetrafluoroethylene-based triboelectric nanogenerator for energy harvesting. Nano Energy 2019, 60, 903-911. [CrossRef]

30. Ahmed, A.; Hassan, I.; El-Kady, M.F.; Radhi, A.; Jeong, C.K.; Selvaganapathy, P.R.; Zu, J.; Ren, S.; Wang, Q.; Kaner, R.B. Integrated triboelectric nanogenerators in the era of the internet of things. Adv. Sci. 2019, 6, 1802230. [CrossRef]

31. Yoon, H.-J.; Ryu, H.; Kim, S.-W. Sustainable powering triboelectric nanogenerators: Approaches and the path towards efficient use. Nano Energy 2018, 51, 270-285. [CrossRef] 
32. Li, M.; Wang, D.; Li, J.; Pan, Z.; Ma, H.; Jiang, Y.; Tian, Z. Facile hydrothermal synthesis of MoS2 nano-sheets with controllable structures and enhanced catalytic performance for anthracene hydrogenation. RSC Adv. 2016, 75, 71534-71542. [CrossRef]

33. Niu, S.; Wang, S.; Lin, L.; Liu, Y.; Zhou, Y.S.; Hu, Y.; Wang, Z.L. Theoretical study of contact-mode triboelectric nanogenerators as an effective power source. Energy Environ. Sci. 2013, 6, 3576-3583. [CrossRef]

34. Ouyang, H.; Tian, J.; Sun, G.; Zou, Y.; Liu, Z.; Li, H.; Zhao, L.; Shi, B.; Fan, Y.; Wang, Z.L.; et al. Self-powered pulse sensor for antidiastole of cardiovascular disease. Adv. Mater. 2017, 29, 1703456. [CrossRef]

35. Yang, J.; Chen, J.; Su, Y.; Jing, Q.; Li, Z.; Yi, F.; Wen, X.; Wang, Z.; Wang, Z.L. Eardrum-inspired active sensors for self-powered cardiovascular system characterization and throat-attached anti-interference voice recognition. Adv. Mater. 2015, 27, 1316-1326. [CrossRef] [PubMed]

36. Pu, X.; Guo, H.; Chen, J.; Wang, X.; Xi, Y.; Hu, C.; Wang, Z.L. Eye motion triggered self-powered mechnosensational communication system using triboelectric nanogenerator. Sci. Adv. 2017, 3, e1700694. [CrossRef]

37. Park, J.H.; Wu, C.; Sung, S.; Kim, T.W. Ingenious use of natural triboelectrification on the human body for versatile applications in walking energy harvesting and body action monitoring. Nano Energy 2019, 57, 872-878. [CrossRef]

38. Chen, X.; Miao, L.; Guo, H.; Chen, H.; Song, Y.; Su, Z.; Zhang, H. Waterproof and stretchable triboelectric nanogenerator for biomechanical energy harvesting and self-powered sensing. Appl. Phys. Lett. 2018, 112, 203902. [CrossRef]

39. Li, Z.B.; Li, H.Y.; Fan, Y.J.; Liu, L.; Chen, Y.H.; Zhang, C.; Zhu, G. Small-sized, lightweight, and flexible triboelectric nanogenerator enhanced by PTFE/PDMS nanocomposite electret. ACS Appl. Mater. Interfaces 2019, 11, 20370-20377. [CrossRef]

40. Wu, C.; Kim, T.W.; Park, J.H.; An, H.; Shao, J.; Chen, X.; Wang, Z.L. Enhanced Triboelectric Nanogenerators Based on MoS2 Monolayer Nanocomposites Acting as Electon-Acceptor Layers. ACS Nano 2017, 11, 8356-8363. [CrossRef]

41. Sahatiya, P.; Kannan, S.; Badhulika, S. Few layer MoS2 and in situ poled PVDF nanofibers on low cost paper substrate as high performance piezo-triboelectric hybrid nanogenerator: Energy harvesting from handwriting and human touch. Appl. Mater. Today 2018, 13, 91-99. [CrossRef]

42. Kim, M.; Kim, S.H.; Park, M.U.; Lee, C.; Kim, M.; Yi, Y.; Yoo, K. MoS2 triboelectric nanogenerators based on depletion layers. Nano Energy 2019, 65, 104079. [CrossRef]

43. Karmakar, S.; Kumbhakar, P.; Maity, K.; Mandal, D.; Kumbhakar, P. Development of flexible self-charging triboelectric power cell on paper for temperature and weight sensing. Nano Energy 2019, 63, 103831. [CrossRef]

44. Kim, M.; Park, D.; Alam, M.M.; Lee, S.; Park, P.; Nah, J. Remarkable Output Power Density Enhancement of Triboelectric Nanogenerators via Polarized Ferroelectric Polymers and Bulk MoS2 Composites. ACS Nano 2019, 13, 4640-4646. [CrossRef] 